\title{
Recent Advances in the Management of Penile Cancer: A Contemporary Review of the Literature
}

\author{
Carlos E. Stecca · Marie Alt · Di Maria Jiang · Peter Chung • \\ Juanita M. Crook · Girish S. Kulkarni · Srikala S. Sridhar
}

Received: November 9, 2020 / Accepted: December 18, 2020 / Published online: January 16, 2021

(C) The Author(s) 2021

\section{ABSTRACT}

Penile cancer is a rare condition, which mostly affects men in their sixth decade of life. The most common histology is squamous cell carcinoma (SCC), with about half of the cases linked to human papilloma virus (HPV) infection. The lack of awareness and significant social and psychological stigma associated with penile cancer often leads to delays in presentation, diagnosis and management. Timely multidisciplinary care at experienced centers is therefore critical for improving outcomes. For patients with advanced disease, treatment options are limited and prognosis remains poor. Large international efforts

C. E. Stecca · M. Alt · D. M. Jiang - S. S. Sridhar ( $₫)$ Division of Medical Oncology and Hematology, Princess Margaret Cancer Centre, Toronto, Ontario, Canada

e-mail: srikala.sridhar@uhn.ca

P. Chung

Department of Radiation Oncology, Princess

Margaret Cancer Centre, Toronto, Ontario, Canada

J. M. Crook

Department of Radiation Oncology, BC Cancer

Agency Sindi Ahluwalia Hawkins Centre for the

Southern Interior, Vancouver, British Columbia,

Canada

G. S. Kulkarni

Division of Urology, Departments of Surgery and

Surgical Oncology, Princess Margaret Cancer

Centre, University of Toronto, Toronto, Ontario,

Canada are underway to further define the optimal standards of care. Targeted therapies and immune checkpoint inhibitors could potentially play a role in advanced disease and are under evaluation in clinical trials. In this review, we discuss the current management of penile cancer and future directions.

Keywords: Carcinoma; Checkpoint inhibitors; HPV; Penile cancer; Penis; Review; Squamous cell

\section{Key Summary Points}

Penile cancer is a rare disease, that has seen limited progress over the last three decades.

A brief overview of the epidemiology and challenges in both diagnosis and treatment are outlined here.

A multimodal approach, involving surgery, radiotherapy and chemotherapy, is imperative for optimizing patient outcomes.

Several trials are currently underway evaluating novel therapeutic strategies and approaches which may hopefully translate into improved patient outcomes in the near future. 


\section{DIGITAL FEATURES}

This article is published with digital features, including a summary slide, to facilitate understanding of the article. To view digital features for this article go to https://doi.org/10.6084/ m9.figshare.13397396.

\section{INTRODUCTION}

Penile cancer is a rare malignancy with an incidence of less than one case per 100,000 men. In the United States, it accounts for an estimated 2200 new cases and 440 deaths annually. There is however significant geographic variation in incidence, likely due to differences in the prevalence of human papilloma virus (HPV) infection, smoking, circumcision and social risk factors [1-3]. Despite appropriate treatment, the 5-year survival is only $50 \%$ in an overall stage-independent analysis, and only $27 \%$ in patients with nodepositive disease [4]. A multidisciplinary approach, preferably in high-volume specialized centers, is therefore imperative for developing an optimal management plan, helping to standardize care and facilitating recruitment to clinical trials $[5,6]$.

Prognosis in the metastatic setting remains poor, as systemic therapy options are very limited. However, better molecular and genomic characterization of penile cancers may pave the way for clinical trials evaluating novel therapies. Since programmed death-ligand 1 (PD-L1) is expressed in at least $30-50 \%$ of penile cancers $[7,8]$, there may also be a role for the immune checkpoint inhibitors (ICI) which are currently being studied in a number of ongoing clinical trials. We undertook this review to promote awareness of this rare disease among care providers, highlight optimal treatment strategies and discuss ongoing research efforts and clinical trials.

\section{METHODS}

We conducted an extensive literature research using PubMed/Medline databases, Scopus,
Science Direct, Google Scholar, American Society of Clinical Oncology (ASCO) abstracts, guidelines in penile cancer and ClinicalTrials.gov. Key words used for the search included penile cancer, squamous cell carcinoma (SCC), immunotherapy, immune-oncology, checkpoint inhibitors, HPV, circumcision, molecular biology and chemotherapy. We also sought multidisciplinary input from surgeons and radiation oncologists in Canada, who are experts in treating this disease.

\section{Compliance with Ethics Guidelines}

This article is based on previously conducted studies and does not contain any new studies with human participants or animals performed by any of the authors.

\section{EPIDEMIOLOGY, RISK FACTORS AND PATHOGENESIS}

\section{Epidemiology}

Although the incidence of penile cancer has been increasing over the past decade, it remains a rare disease, accounting for only $0.2 \%$ of all male cancers in the United States [1]. In developing countries like Brazil, however, it accounts for $2 \%$ of all male cancers, while in Israel rates are close to zero, likely due to neonatal circumcision [2, 3]. There are no differences between white and black races, but a $72 \%$ higher incidence is seen in Hispanics compared to non-Hispanics and lower incidence is seen in Asians. [9]. The median age at diagnosis of penile cancer is 60 , though it can also manifest in younger patients [2]. In a population-based study, married men had a lower incidence than single men, possibly reflecting fewer sexual partners, less exposure to HPV and fewer risk factors such as inflammatory penile conditions and phimosis $[3,10]$.

\section{Risk Factors}

Risk factors and protective factors for penile cancer are highlighted in Table 1. 
One of the main risk factors for penile cancer is smoking. A report by Daling et al. showed a twofold increase in penile cancer in smokers [22], with other studies from Brazil and the USA confirming this association [23, 24].

HPV infection, especially strains $16,18,31$ and 33 , is another key risk factor $[25,26]$. Routine male HPV vaccination has been recommended since 2012 in countries like Canada [27], and has been shown to decrease the incidence of genital warts by $90 \%$. Its protective effect against penile cancer has not yet been shown, but this is likely due to the low overall incidence of penile cancer and time required to see this effect [28].

Several studies have demonstrated that neonatal circumcision reduces the incidence of penile cancer by promoting better hygiene and decreasing chronic inflammatory conditions like balanoposthitis and lichen sclerosus et atrophicus, two key risk factors for penile cancer [28-32]. However, circumcision does not completely eliminate the risk of penile cancer $[3,20]$. In addition, circumcision after the neonatal period may not offer the same degree of protective benefit against penile cancer [11]. Across the world, circumcision rates vary, with rates as low as $0.1 \%$ in Bolivia and above $90 \%$ in Israel and Turkey [33], owing to differing recommendations from pediatric guidelines as well as social and religious practices [34, 35]. With a greater emphasis on hygiene and sexually transmitted disease protection strategies including vaccines against HPV, the need for neonatal circumcision may be decreasing [34].

\section{PATHOGENESIS AND MOLECULAR BIOLOGY}

Pathogenesis of penile cancer can be subdivided into HPV-dependent and HPV-independent pathways. Precancerous lesions associated with high-risk HPV occurs from the integration of viral DNA into the host genome, leading to overexpression of oncogenes (E6 and E7) responsible for malignant transformation. These oncogenes are involved in the disruption of centrosome synthesis required for mitosis, resulting in the development of multipolar mitoses, associated with both premalignant and malignant HPV-related lesions [36]. E6 and E7 may also lead respectively to inactivation of the p53 and RB1 genes, thereby allowing uncontrolled cell proliferation [37].

HPV-independent penile cancers are commonly associated with a premalignant precursor lesion related to chronic inflammation. Reactive oxygen/nitrogen species (ROS/RNS) produced by inflammatory cells are involved in the development of a variety of cancers. One possible pathway for carcinogenesis in this context is the loss of heterozygosity of p16, a tumor suppressor gene, which is frequently observed in penile cancer. Other possible pathways include the overexpression of inflammatory mediators such as prostaglandin E2 (PGE2), which may lead to activation of the epidermal growth factor receptor (EGFR), $\beta$-catenin/T-cell factor and PI3K, which are known to play important roles in carcinogenesis [36].

Overexpression of EGFR is almost universal and correlates with grade in penile cancer. It is more common among HPV-negative tumors and correlates with the phosphorylation and activation of AKT signaling. HER3 and HER4 proteins are also overexpressed and are more frequent in HPV-positive tumors [38]. Epigenetic alterations may also play a role in the prognosis of penile cancer. A study by Guerrero et al. suggested that hypermethylation of thrombospondin 1 (TSP-1), RASSF1A and p16 genes likely contribute to disease progression [39].

\section{HISTOLOGICAL ASSESSMENT}

Approximately $95 \%$ of primary penile cancers are SCCs [40], and can be subclassified into several histologic variants, including the usual type, warty, basaloid, papillary, verrucous, sarcomatoid and mixed [41]. Basaloid, adenosquamous and sarcomatoid subtypes are associated with high-grade, aggressive tumors. Unlike cervical SCC, where almost all cases are secondary to HPV infection, in penile cancer this association with HPV only ranges between 35 and 50\% [41]. Histological subtypes that are HPV-related and non-HPV-related are shown in 
Table 1 Risk factors and protective factors associated with penile cancer

\begin{tabular}{ll}
\hline Risk factors & Protective factors \\
\hline Smoking (OR: 2.3) [11] & Circumcision (OR: 1.0) [11, 20, 21] \\
Inflammatory conditions (OR:3.9) [12] & Conservative sexual behavior (OR: 1.0) [13] \\
Phimosis (OR: 11.4) [13] & High educational level (OR: 0.7) [13] \\
HPV infection (OR: 2.3) [14] & \\
Obesity (OR: 1.53) [15, 16] & \\
Multiple sexual partners (OR: 2.4) [13] & \\
Low disposable income (OR: 1.26) [17] & \\
Previous ultraviolet photo-chemotherapy (PUVA) (OR: 58.8) [18] & \\
HIV (IRR 3.9-8.0) [19] & \\
\hline OR odds ratio, IRR incidence rate ratio &
\end{tabular}

Table 2 [42]. Detection of p16 by immunohistochemistry is a reliable indicator for the presence of high-risk HPV DNA [40]. A study by Cubilla et al. demonstrated that $\mathrm{p} 16$ positivity is strongly associated with the presence of highrisk HPV genotypes, while its negativity could represent either absence of HPV DNA or infection by a low-risk genotype. Concordance between p16 and HPV by polymerase chain reaction is approximately $80 \%$ [40]. Whether patients with HPV-related penile cancer have a better prognosis than those without remains inconclusive [43], and to date there are no differences in the approach to treatment.

\section{CLINICAL PRESENTATION, DIAGNOSIS AND STAGING}

\section{Clinical Presentation and Initial Evaluation}

Most penile cancers arise on the glans, coronal sulcus or foreskin (Fig. 1) [45]. Generally, a visible or palpable lesion manifests as a painless lump or ulcer (Fig. 2) [46], but less specific presentations such as erythema or a rash may also occur [47]. Approximately $25 \%$ of patients have a history of a pre-existing penile skin condition, such as balanitis xerotica obliterans, phimosis, chronic inflammation, Bowen's disease, genital warts, erythroplasia of Queyrat, keratotic lesions or dysplasia [47]. Nodal dissemination may be present at diagnosis and may be clinically evident on physical exam. Inguinal lymph nodes are palpable in $28-64 \%$ of patients at presentation, and disease will already be metastatic in 47-85\% (Fig. 3) [48]. Distant metastases are less common until later in the disease course $(<3-5 \%$ at presentation) [49].

Unfortunately, delays in diagnosis of more than 6 months are not uncommon. The main reasons include social stigma and psychological consequences in describing the problem to their doctor or partner, insidious and nonspecific initial symptoms, concomitant phimosis masking the malignant lesion, and lack of awareness of the condition [50]. On the other hand, factors positively associated with men's help-seeking behavior include social support from spouses and general knowledge about cancer [51]. Progressive disease during delays in seeking medical attention can lead to a significant impairment of erectile and orgasmic function, sexual desire and intercourse satisfaction [52].

Baseline evaluation should include a detailed physical examination of the penis and inguinal lymph nodes, as well as a complete history to identify any potential risk factors for penile 
Table 2 World Health Organization classification of tumors of the penis

WHO classification of tumors of the penis [44]

\begin{tabular}{ll}
\hline Non-HPV-related & HPV-related \\
\hline SCC, usual type & Basaloid SCC \\
Pseudohyperplastic carcinoma & Papillary basaloid carcinoma \\
Verrucous carcinoma & Warty carcinoma \\
Carcinoma cuniculatum & Warty-basaloid carcinoma \\
Papillary carcinoma NOS & Clear-cell carcinoma \\
Adenosquamous carcinoma & Lymphoepithelioma-like carcinoma \\
Sarcomatoid carcinoma & \\
Mixed squamous cell carcinoma & \\
\hline
\end{tabular}

$S C C$ squamous cell carcinoma, NOS not otherwise specified

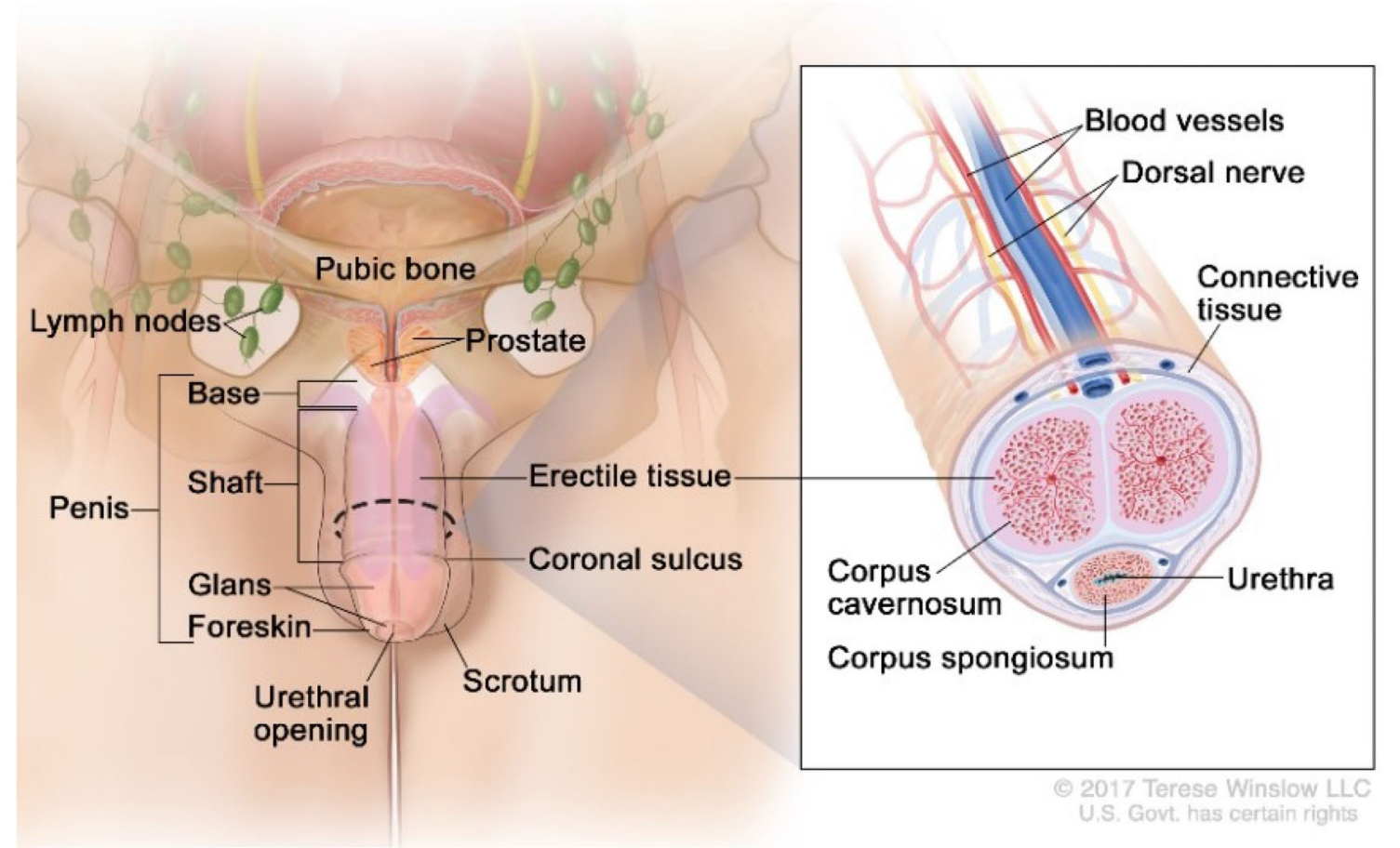

Fig. 1 Anatomy of the penis. Reproduced with permission from Winslow 2017. Anatomy Of The Penis. [image] Available at: https://visualsonline.cancer.gov/details.cfm?imageid=11321 Accessed 17 October 2020]

cancer. Primary lesions are assessed by careful inspection and palpation, with clear documentation of morphological and physical characteristics [53]. Penile cancer should be suspected in all men with a penile mass or an ulcerating penile lesion, especially in the setting of palpable groin lymph nodes. Also, lesions that are not improving after a short trial of antibiotics or 


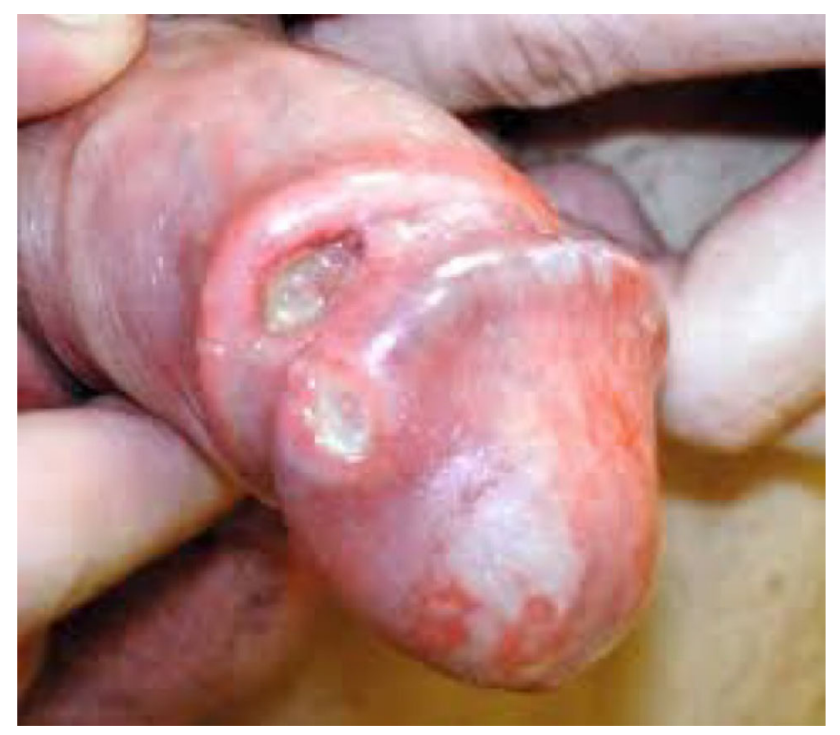

Fig. 2 Penile cancer manifested as ulcerative lesion. Reproduced with permission from Penile cancer 01, digital photograph, The British Association of Urological Surgeons, accessed 06 December 2020

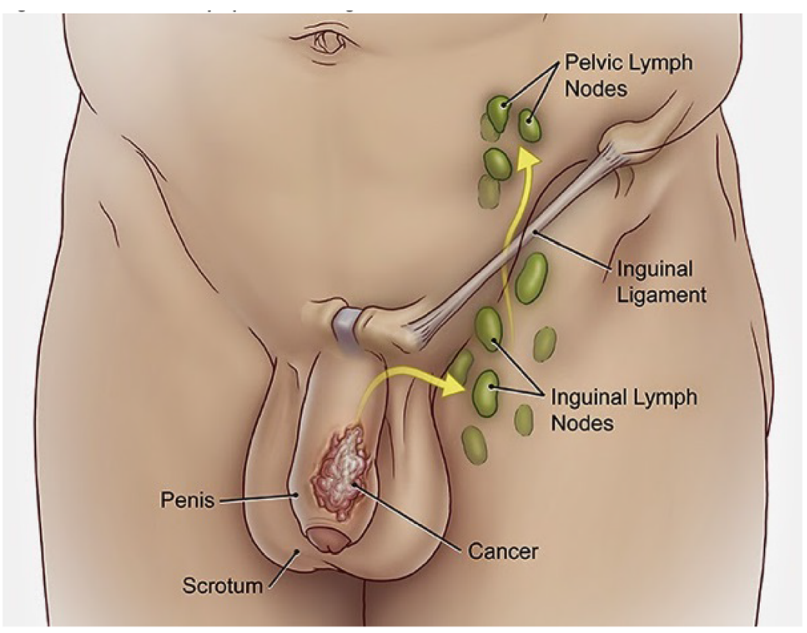

Fig. 3 Penile cancer lymphatic drainage. Reproduced with permission from Lymph nodes and penile cancer, The British Association of Urological Surgeons, accessed 06 December 2020

topical steroids should be biopsied to rule out malignancy [49].

Diagnosis of penile cancer requires tissue confirmation. The preferable method to obtain a tissue sample of the primary lesion is through an incisional biopsy, including tumor and surrounding normal tissue in the sample. Other accepted methods include tissue core biopsy, brush biopsy and excisional biopsy [49].

\section{Staging Evaluation}

Penile cancer is staged according to the American Joint Committee on Cancer/Union for International Cancer Control (AJCC/UICC) eighth edition (Table 3) [54].

Ultrasound or magnetic resonance imaging (MRI) with an artificial erection is often used to characterize infiltration of the corpora for local staging purposes [55]. In patients with $\geq \mathrm{T} 1$ 
grade 2 disease and clinically non-palpable inguinal lymph nodes, micro-metastases can be found in up to one quarter of cases; therefore, dynamic sentinel node biopsy (DSNB) is indicated $[44,52]$. If palpable inguinal lymph nodes are present, computed tomography (CT) of the thorax, abdomen and pelvis [56] is required for nodal and distant staging.

18F-Fluorodeoxyglucose (FDG) positron emission tomography (PET) may have greater sensitivity in detecting pelvic lymph nodes and distant metastases (up to 88\%) than conventional imaging [57]. However, whether this translates into improved outcomes is unknown, and more studies are needed before implementing PET/CT in routine practice.

\section{MANAGEMENT}

To date, there are no randomized trials guiding the management of penile cancer. Multidisciplinary discussions at experienced centers are critical, with consideration for risk of local, regional and systemic recurrence, along with morbidity of the proposed treatment, impact on patient's quality of life and patient preferences. Centralized care in specialized hospitals that serve a population of at least 4 million people, managing at least 25 new penile cancer cases per year, has been recommended by the National Institute for Health and Care Excellence (NICE), to ensure optimal patient outcomes [58].

Treatment options for loco-regional disease includes surgical resection and organ-sparing strategies (described below), while for patients with recurrent or metastatic disease, systemic therapy is the cornerstone (Figs. 4 and 5).

\section{Approach to Primary Tumor and Lymph Nodes}

Treatment of the primary tumor should include consideration for organ-sparing modalities. For noninvasive disease, besides conservative surgery, topical agents [59] and excisional procedures using carbon dioxide (CO2) and neodymium are possible options [49]. For both low- and intermediate-grade T1 lesions, penile- sparing surgeries including Mohs micrographic surgery, circumcision, local excision and partial glansectomy are all acceptable strategies [60-64].

Patients with high-grade T1 disease and beyond often require more extensive surgical interventions, such as partial and total penectomy [53], depending on tumor features and depth of invasion. However, radiotherapy, particularly brachytherapy, can also be considered as an organ-sparing alternative [53, 56, 65-67], and can achieve successful penile preservation in $70-80 \%$ of cases. If this modality is not available, external beam radiotherapy (EBRT) is an alternative that can prevent amputation in $50-60 \%$ of patients [68]. A study by Rozan et al. demonstrated a $78 \%$ organ preservation rate with brachytherapy, as opposed to only $64 \%$ for those receiving EBRT [69] (Fig. 4).

Since lymph node involvement is a key prognostic factor, evaluation of the lymph nodes by physical exam and imaging is critical [70]. Despite clinically node-negative disease, the risk of micro-metastases is as high as $25 \%$ depending on the stage, grade and presence of lymphovascular invasion of the primary tumor. Invasive nodal staging with either DSNB or by modified inguinal lymphadenectomy is recommended for disease greater than Tis, Ta and T1G1 [56, 61, 71]. In patients with clinically node-positive disease $(\mathrm{cN}+)$, fine needle aspiration (FNA) is recommended, and if negative, a confirmatory excisional biopsy is usually performed, followed by surveillance or inguinal lymph node dissection (ILND) according to the result. If FNA is positive, the recommended approach is to proceed with radical ILND for most cN1 disease or neoadjuvant chemotherapy if cN2 or cN3 [66] (Fig. 5).

The French study AFU-GETUG 25 (NCT02817958) is currently enrolling patients and aims to assess a multimodal approach for lymph node metastasis in penile SCCs. Patients will be allocated to one of two treatment arms: arm A, lymphadenectomy (plus or minus sentinel node) and adjuvant chemotherapy, or arm $B$, neoadjuvant chemotherapy followed by bilateral lymphadenectomy. The selected regimen is TIP (paclitaxel, ifosfamide and cisplatin) for four cycles every 21 days. Results of this 
Table 3 AJCC 8th edition for both clinical and pathological staging

Primary tumor $(\mathrm{T})$

$T$ category

$\mathrm{Tx}$

T0

Tis

$\mathrm{Ta}$

$\mathrm{T} 1$

T1a

$\mathrm{T} 1 \mathrm{~b}$

$\mathrm{T} 2$

T3

$\mathrm{T} 4$

Regional nodes $(\mathrm{N})$

Clinical $\mathrm{N}$ category

$\mathrm{cNx}$

$\mathrm{cN} 0$

$\mathrm{cN} 1$

$\mathrm{cN} 2$

$\mathrm{cN} 3$

Pathological N

$\mathrm{pNx}$

pN0

$\mathrm{pN} 1$

$\mathrm{pN} 2$

$\mathrm{pN} 3$
T criteria

Primary tumor cannot be assessed

No evidence of primary tumor

Carcinoma in situ [penile intraepithelial neoplasia (PeIN)]

Noninvasive localized squamous cell carcinoma

-Glans: Tumor invades lamina propria

-Foreskin: Tumor invades dermis, lamina propria, or dartos fascia

-Shaft: Tumor invades connective tissue between epidermis and corpora regardless of location

Tumor is without lymphovascular invasion or perineural invasion and is not high grade (i.e., grade 3 or sarcomatoid)

Tumor exhibits lymphovascular invasion and/or perineural invasion or is high grade (i.e., grade 3 or sarcomatoid)

Tumor invades corpus spongiosum (either glans or ventral shaft) with or without urethral invasion Tumor invades corpus cavernosum (including tunica albuginea) with or without urethral invasion Tumor invades adjacent structures (i.e., scrotum, prostate, pubic bone)

\section{Clinical $N$ criteria}

Regional lymph nodes cannot be assessed

No palpable or visibly enlarged inguinal lymph nodes

Palpable mobile unilateral inguinal lymph node

Palpable mobile $\geq 2$ unilateral inguinal nodes or bilateral inguinal lymph nodes

Palpable fixed inguinal nodal mass or pelvic lymphadenopathy unilateral or bilateral

\section{Pathological N criteria}

Lymph node metastasis cannot be established

No lymph node metastasis

$\leq 2$ unilateral inguinal metastases, no ENE

$\geq 3$ unilateral inguinal metastases or bilateral metastases, no ENE

ENE of lymph node metastases or pelvic lymph node metastases

Distant metastasis $(\mathrm{M})$

$\mathrm{M}$ category

M0

M1
M criteria

No distant metastasis

Distant metastasis present 
Table 3 continued

Histologic grade $(G)$
Gx
Grade cannot be assessed
G1
Well differentiated
G2
Moderately differentiated
G3
Poorly differentiated/high grade

Prognostic stage groups

Stage 0 (0is, 0a)

Tis-Ta N0 M0

Stage I

T1a N0 M0

Stage IIA

T1b-T2 N0 M0

Stage IIB

T3 N0 M0

Stage IIIA

T1-T3 N1 M0

Stage IIIB

T1-T3 N2 M0

Stage IV

$\mathrm{T} 4$ or/and N3 or/and M1

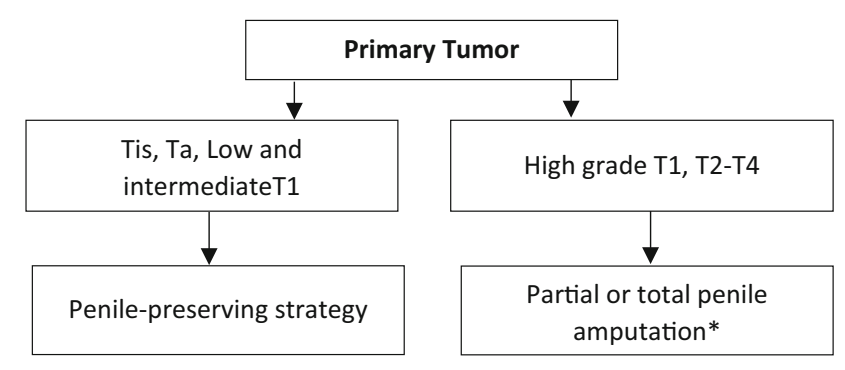

Fig. 4 Management of primary tumor

prospective phase II study are anxiously awaited, as they may help to guide management and optimize patient outcomes.

\section{Chemotherapy}

\section{Neoadjuvant Chemotherapy}

Patients with fixed or bulky inguinal lymph nodes $(\geq 4 \mathrm{~cm})$, bilateral palpable lymph nodes or pelvic node involvement should be offered multimodal therapy with neoadjuvant chemotherapy (NAC). The primary goal of NAC is to eliminate micro-metastases and shrink the tumor to facilitate surgery. Four cycles of TIP is currently the recommended regimen, based on a single-arm phase II trial showing an objective response rate (ORR) of $50 \%$, a pathological complete response (pCR) rate of $10 \%$ and median overall survival (mOS) of 17.1 months [72]. In a retrospective review, Dickstein et al. reported an ORR of $65 \%$ for 61 patients receiving TIP, with $85 \%$ of patients subsequently undergoing surgery. For patients who achieved a partial response (PR)/pCR, the 5-year mOS was $50 \%$, as opposed to $25 \%$ and $7.7 \%$ with stable or progressive disease, respectively [73]. Based on promising results from head and neck SCC, TPF (paclitaxel, cisplatin, and 5-fluorouracil) was tested, but showed poor tolerance and disappointing outcomes [74]. 


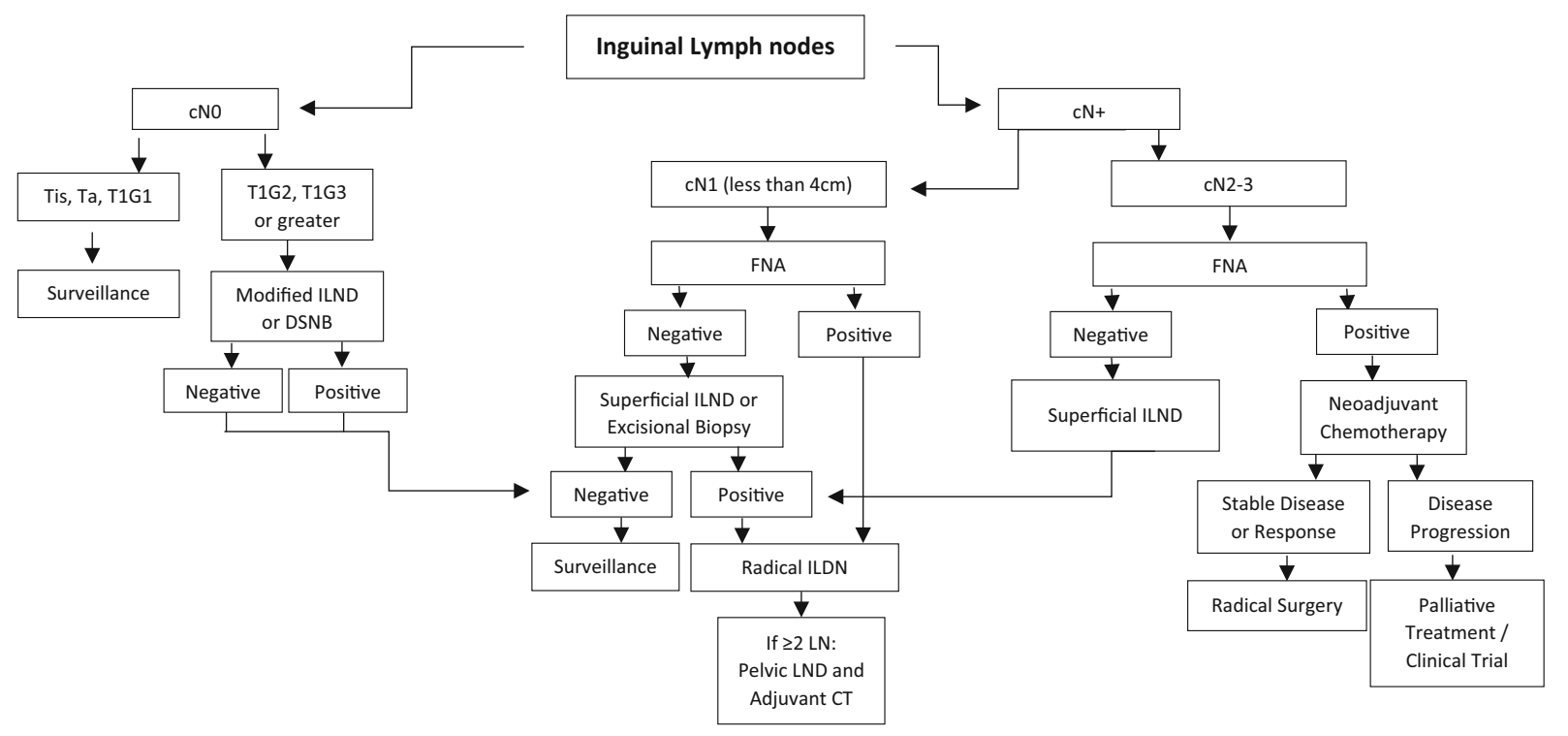

$\mathrm{cN}$ : clinical lymph node status; ILND: inguinal lymph node dissection

* Radiotherapy can be considered in selected cases (i.e. after circumcision T1b,T2, less than $4 \mathrm{~cm}$ in

diameter and no or minimal extension onto the penile shaft)

Fig. 5 Management of lymph nodes

Because of decreased performance status, some patients may not tolerate triplet regimens; therefore, options like cisplatin combined with 5-fluorouracil or irinotecan are also considered, based on extrapolation from advanced disease data, and described in greater detail below $[75,76]$. For patients ineligible to receive cisplatin, a feasible option is carboplatin plus paclitaxel [52].

\section{Adjuvant Chemotherapy}

In patients not receiving NAC, adjuvant chemotherapy (AC) is recommended if there is bilateral inguinal lymph node involvement (pN2), pelvic lymph node or extra-nodal extension (N3) [56, 66]. A retrospective study by Sharma et al. demonstrated that patients with pelvic lymph node involvement who received platinum-based chemotherapy had mOS of 21.7 versus 10.1 months in patients who did not $(p=0.048)$ [77]. The recommended regimen, extrapolating from the NAC setting, is four cycles of TIP [72].

\section{Radiotherapy}

\section{Adjuvant Treatment and Chemo-Radiation}

To date, adjuvant radiotherapy has not been rigorously evaluated. A recent systematic review [78] with data from 1605 men spanning over 40 years suggested that the radiotherapy for patients with disease involving $\geq 2$ inguinal nodes or extra-nodal extension can be considered; however, no survival difference was identified [77, 79]. There was significant heterogeneity in patient management, minimal detail describing selection criteria for radiotherapy or radiotherapy techniques, and lack of detail around surgery. In essence, many studies included in the review did not reflect modern penile cancer management. Overall, the quality of the evidence in this review was extremely limited, and therefore radiotherapy is not routinely recommended outside of clinical trials [77, 79].

Current practice extrapolates from the level 1 evidence from clinical trials in squamous carcinoma of the vulva, which has similar nodal 
drainage patterns and similar bimodal etiology paths-either HPV or chronic inflammation. Trials of radiotherapy and chemoradiotherapy have demonstrated both excellent response rates and improved mOS, establishing chemoradiation as the standard of care for locally advanced vulvar cancer [80-83]. Chemoradiotherapy is also established in other HPV-related tumors, suggesting further study in penile cancer is warranted. In patients with penile cancer and palapable or radiologically evident inguinal lymph node metastases, the InPACT (NCT02305654) Phase III trial, is an important trial which aims to determine the relative benefits and sequencing of surgery, chemotherapy and chemoradiotherapy. This trial is currently open and accruing and will hopefully provide prospective data on the optimal approach in this patient population [84].

\section{Psychological Impact}

Due to the stigma associated with this disease and treatment, the involvement of a supportive/psychosocial care team is also very important, especially if penectomy is being considered. Levels of depression in patients with penile cancer treated surgically are comparable to other urologic malignancies, but anxiety levels are usually higher when compared to patients undergoing other procedures, like cystectomy [85] Although most patients undergoing partial penectomy have sufficient erectile function for sexual intercourse and ejaculation, there is a clear decrease in the sexual satisfaction related to self-esteem concerns. However, there seems to be no difference in other aspects of quality of life, indicating that patients usually adapt over time following radical treatment [85]. Reconstructive surgeries may be feasible, with outcomes depending on the extent of initial surgery. A multidisciplinary discussion including plastic surgery may also be required up front, again highlighting the importance of treatment in specialized centers with expertise in managing all aspects of this disease.

\section{Metastatic Disease}

\section{Palliative Chemotherapy}

Outcomes in advanced disease remain poor, with an estimated mOS of only 7-8 months $[75,86]$. Systemic chemotherapy is the standard of care for patients with unresectable locally advanced or metastatic disease; however, treatment outcomes remain suboptimal. Enrollment in clinical trials should be encouraged if available. Treatment decisions generally take into consideration symptom burden, tolerability and patient preference. Given the poor outcomes, best supportive care and early discussion of palliative care is critical.

For patients with advanced disease, the presence of visceral metastasis (VM) and performance status (PS) $\geq 1$ are factors associated with poor prognosis [87], and more recently it has been shown that, after controlling for VM and PS, the expression of the MAML2 gene was independently associated with poor OS [77]. The KITLG and JAK1 genes were also associated with poor OS, and may warrant evaluation as potential therapeutic targets [88].

Cisplatin-based regimens are the most commonly used; however, no standard exists due to a lack of comparative trials. The largest prospective trial to date evaluating first-line chemotherapy was a phase II study of 45 patients evaluating a triplet regimen of cisplatin, methotrexate and bleomycin. The ORR was $32.5 \%$, and mOS was 28 weeks, but treatment-related mortality was high at $13.9 \%$, mostly due to pulmonary complications or pneumonitis [86]. Bleomycin-based regimens are therefore not recommended.

The most widely used first-line regimen recommended by the National Comprehensive Cancer Network (NCCN) guidelines [66] is TIP, based on data from the neoadjuvant trial by Pagliaro et al. [70], reporting an ORR of 50\% and pCR of $10 \%$. Toxicity was high, with $17 \%$ grade 3 or 4 infection, but no fatalities were reported [72]. In this patient population, given the location of the disease, infection is a major concern. Other first-line treatment options include cisplatin plus 5-fluorouracil, which had a PR rate of $32 \%$ in a small retrospective trial 
[75], and cisplatin plus irinotecan, with a PR rate of $30.8 \%$ reported in a phase II trial [76].

For patients unfit for cisplatin, a relatively well-tolerated option is carboplatin plus paclitaxel [21]. Vinflunine was also recently tested in 25 patients in the first-line setting and demonstrated an ORR of $27.3 \%$, comparable to other phase II trials [89].

Prognosis is poor for patients with platinum refractory disease, with mOS of $<6$ months. There is very limited data supporting the use of second-line therapy. For patients opting for further treatment, taxane chemotherapy is an option. Paclitaxel showed a 20\% ORR, with progression-free survival (PFS) of 11 weeks and a mOS of 23 weeks in a phase II trial [90]. Whenever possible, these patients should be enrolled in clinical trials.

\section{NEW PERSPECTIVES IN ADVANCED PENILE CANCER TREATMENT}

\section{Targeted Therapies}

Unfortunately, response to chemotherapy is often limited and short-lived for most patients [66], underscoring the need for novel therapeutic strategies. Advances in our basic understanding of this disease and promising developments in the areas of targeted therapies and immunotherapy may improve outcomes.

A study by Jacob et al. evaluated the genomic profile of 78 metastatic penile cancer patients using next-generation sequencing technology. More than one quarter of patients harbored targetable mutations, including NF1, PTEN, BRCA2, ATM, EGFR, FGFR3 and ERBB2, suggesting a putative role for therapies targeting DNA repair, mTOR and tyrosine kinase pathways [91]. Another study, by Chahoud et al., reported the whole exome sequencing analysis of 34 patients, where the most common mutations were found in TP53 (35\%), NOTCH1 (35\%), CDKN2A (23\%), PIK3CA (21\%) and CASP8 (21\%), similar to mutations found in other SCCs [92].

It was observed that ERCC1 amplification and KRAS mutations are rare or absent in this patient population, which may indicate responsiveness to EGFR inhibitors [25]. A retrospective trial assessing the role of the EGFR inhibitor cetuximab, when combined with chemotherapy, demonstrated anti-tumor activity, with an ORR of $23.5 \%$ among 24 patients [93]. Dacomitinib, an irreversible pan-EGFR inhibitor, was tested alone in the first-line setting in a phase II trial and resulted in 32.1\% ORR, with only one (3\%) pCR [94]. The ORPHEUS phase II trial (NCT04231981), assessing the role of INCMGA00012, a drug targeting PI3K and IDO (indoleamine 2,3dioxygenase), is currently recruiting patients with advanced penile cancer. The CaboPen phase II trial (NCT03943602), is also underway studying the role of Cabozantanib, the multi-targeted tyrosine kinase inhibitor which targets the VEGFR2 and MET receptors.

\section{Immune Checkpoint Blockade}

There is also significant interest in exploring novel ICI in penile cancer. Immunotherapy using checkpoint inhibitors, such as anti-programmed death 1 (PD1), anti-PD-L1 and anticytotoxic T-lymphocyte antigen 4 (CTLA4), have emerged as promising treatment options for a variety of cancers, including other HPVassociated neoplasms such as head and neck cancers. Interestingly, PD-L1 expression is present in up to $62 \%$ of primary and metastatic penile SCC $[95,96]$, and the tumor mutational burden (TMB) is similar to other SCCs [92], which provides further rationale for testing ICI in this disease.

Several trials evaluating single-agent antiPD-L1 therapy are underway (Table 3). Avelumab is being tested in penile cancer patients in two ongoing trials: The phase II ALPACA trial (NCT03391479) is actively enrolling patients with locally advanced or metastatic penile cancer unfit for or progressing on platinumbased chemotherapy, and is expected to complete accrual in February 2022. Another trial (NCT03774901) is investigating the role of avelumab as maintenance therapy after PR or stable disease with first-line chemotherapy. This study is particularly interesting because of the recent positive JAVELIN Bladder 100 trial, which showed an overall survival benefit for patients receiving avelumab as maintenance therapy after response or stable disease with 
platinum-based first-line chemotherapy in bladder cancer [97]. The role of avelumab is also being investigated in association with valproic acid (VPA) for patients with advanced p16-positive squamous cell tumors, including penile tumors (NCT03357757). The premise is that VPA could unmask a chronic viral infection and render the tumor susceptible to attack by the immune system. NCT03686332 is a phase II study evaluating the use of atezolizumab with or without radiotherapy in patients with advanced SCC of the penis, defined as inoperable locally advanced (arm A) or metastatic disease (arm B). NCT04224740 is another phase II study recruiting patients with advanced disease to receive pembrolizumab plus standard-of-care chemotherapy (Table 3).

Multiple combination strategies with ICI are also being tested. Cabozantinib has recently been shown to block PI3K signaling in myeloidderived suppressor cells (MDSCs) to enable efficacy from immune checkpoint blockade in metastatic prostate cancer [98] and is now being tested in combination with nivolumab with or without ipilimumab in two ongoing trials (NCT02496208 and NCT03866382) for other metastatic genitourinary tumors, including penile cancer. More recently, at the 2020 American Society of Clinical Oncology meeting, the results of a phase II trial of nivolumab and ipilimumab for advanced rare genitourinary tumors, including $11 \%$ of penile cancers, demonstrated modest activity, with an ORR of $16 \%$ and disease control rate of $45 \%$ [99]. Another interesting and promising phase II trial, conducted by the MD Anderson Cancer Center group, is assessing the role of a vaccine made from a gene-modified HPV virus (MEDI0457) in combination with durvalumab for patients with recurrent or metastatic HPVrelated cancers, including penile cancer (NCT03439085). They hypothesize that the combination of both drugs will provide better anti-tumor activity (Table 4).

In the neoadjuvant setting, a phase II study is evaluating the role of the TIP regimen in combination with triprilimab, an anti PD-1 drug, and nimotuzumab, an EGFR inhibitor, with pCR as the primary endpoint (NCT04475016).
While we await more mature data on immune checkpoint inhibitor efficacy, we can already highlight that this is a safe and welltolerated treatment modality for this patient population, especially when compared to chemotherapy.

\section{CONCLUSIONS}

Advanced penile cancer represents a significant challenge in clinical practice, as options are limited and prospective data are sparse. The rarity of this condition makes it difficult to conduct randomized phase III trials and underscores the importance of at least having good-quality prospective data and large-scale collaborations to assess the optimal delivery of local and systemic therapy in this disease. A multidisciplinary approach with consultation in specialized centers is critical to ensuring optimal outcomes in this devastating disease. Understanding penile cancer at the molecular level holds promise in the development of novel therapeutic approaches to improve treatment outcomes. Penile cancer survivorship programs and support groups may help patients to better cope with the psychological impact of this disease and may increase patient awareness of ongoing research and clinical trials.

\section{ACKNOWLEDGEMENTS}

Funding. No funding or sponsorship was received for this study or publication of this article.

Authorship. All named authors meet the International Committee of Medical Journal Editors (ICMJE) criteria for authorship for this article, take responsibility for the integrity of the work as a whole, and have given their approval for this version to be published.

Disclosures. Di Jiang discloses consulting fees from Bayer. Peter Chung discloses honoraria from abbVie, Boston Scientific, AstraZeneca and TerSera. Juanita Crook discloses a non- 


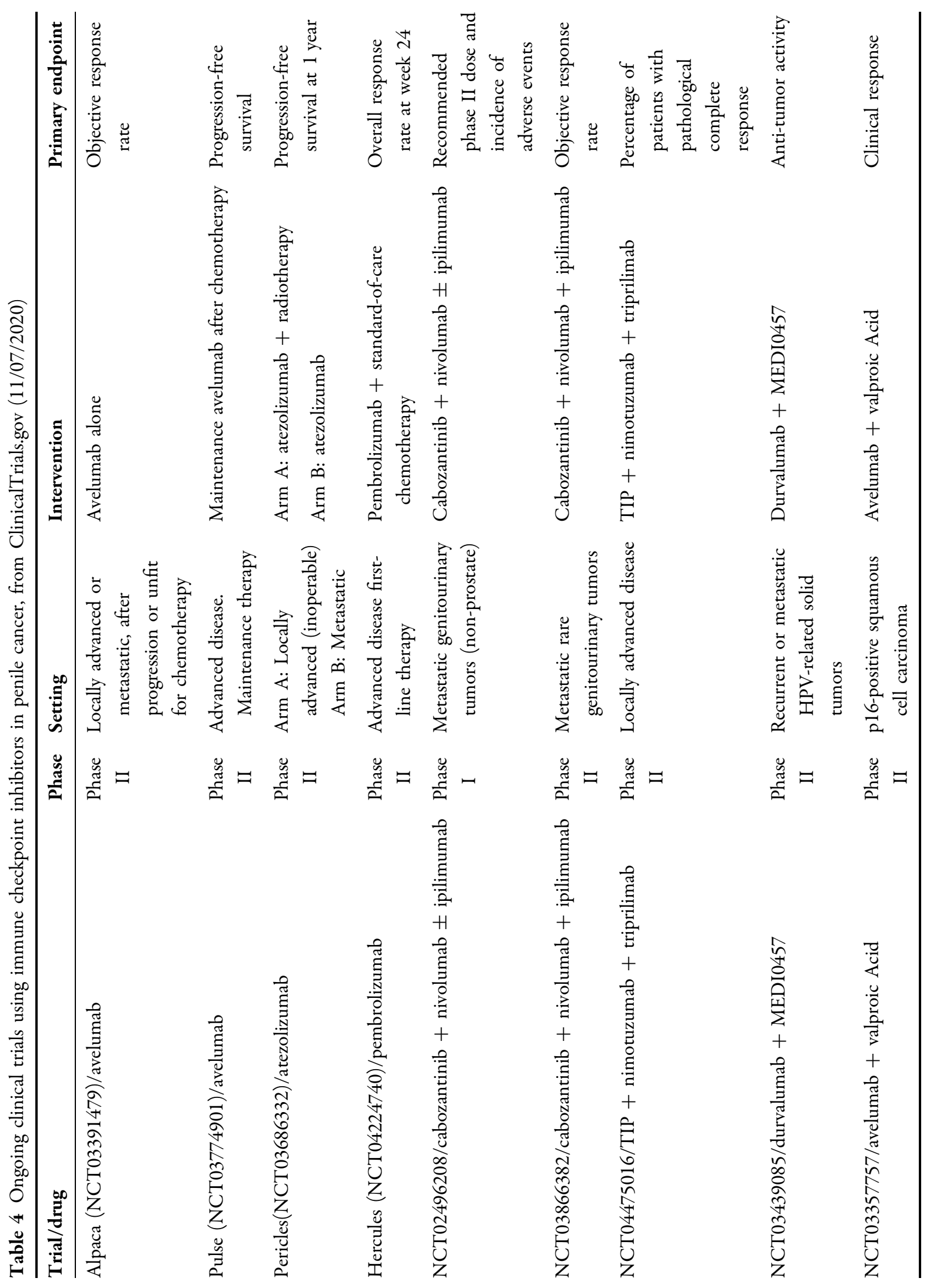


remunerated advisory board position at Concur Breast Microseed and honoraria for teaching sessions for AbbVie, TerSera and Ferring. Girish S. Kulkarni discloses attendance on advisory boards for Roche, Merck, Janssen and Theralase; honoraria from AbbVie, Pfizer, TerSera and Knight Therapeutics, and participation in clinical trials for BMS, AstraZeneca, Theralase, Merck, Janssen, Sesen Bio and Pfizer. Srikala S. Sridhar has received research funding from Bayer and Janssen; and honoraria from Roche, Merck, Pfizer, AstraZeneca, BMS, Janssen, Bayer, Astellas, Sanofi Aventis and Immunomedex. Carlos E. Stecca and Marie Alt have nothing to disclose.

Compliance with Ethics Guidelines. This article is based on previously conducted studies and does not contain any new studies with human participants or animals performed by any of the authors.

Open Access. This article is licensed under a Creative Commons Attribution-NonCommercial 4.0 International License, which permits any non-commercial use, sharing, adaptation, distribution and reproduction in any medium or format, as long as you give appropriate credit to the original author(s) and the source, provide a link to the Creative Commons licence, and indicate if changes were made. The images or other third party material in this article are included in the article's Creative Commons licence, unless indicated otherwise in a credit line to the material. If material is not included in the article's Creative Commons licence and your intended use is not permitted by statutory regulation or exceeds the permitted use, you will need to obtain permission directly from the copyright holder. To view a copy of this licence, visit http:// creativecommons.org/licenses/by-nc/4.0/.

\section{REFERENCES}

1. Siegel RL, Miller KD, Jemal A, et al. Cancer statistics. CA Cancer J Clin. 2020;70:7-30.
2. Favorito LA, Nardi AC, Ronalsa M, et al. Epidemiologic study on penile cancer in Brazil. Int Braz J Urol. 2008;34(5):587-91 (discussion 591-3).

3. Douglawi A, Masterson TA. Penile cancer epidemiology and risk factors: a contemporary review. Transl Androl Urol. 2017;6(5):785-90.

4. Barski D, Georgas E, Gerullis H, Ecke T. Metastatic penile carcinoma: an update on the current diagnosis and treatment options. Cent European J Urol. 2014;67(2):126-32.

5. Kumar P, Singh S, Goddard JC, Terry TR, Summerton DJ. The development of a supraregional network for the management of penile cancer. Ann R Coll Surg Engl. 2012;94(3):204-9.

6. Tang V, Clarke L, Gall Z, et al. Should centralized histopathological review in penile cancer be the global standard? BJU Int. 2014;114(3):340-3.

7. Davidsson S, Carlsson J, Giunchi F, et al. PD-L1 expression in men with penile cancer and its association with clinical outcomes. Eur Urol Oncol. 2019;2(2):214-21.

8. De Bacco MW, Carvalhal GF, MacGregor B, et al. PD-L1 and p16 expression in penile squamous cell carcinoma from an endemic region. Clin Genitourin Cancer. 2020;18(3):e254-9.

9. Hernandez BY, Barnholtz-Sloan J, German RR, et al. Burden of invasive squamous cell carcinoma of the penis in the United States, 1998-2003. Cancer. 2008;113(Suppl10):2883-91.

10. Ulff-Moller CJ, Simonsen J, Marriage FM. Cohabitation and incidence trends of invasive penile squamous cell carcinoma in Denmark 1978-2010. Int J Cancer. 2013;133:1173.

11. Maden C, Sherman KJ, Beckmann AM, et al. History of circumcision, medical conditions, and sexual activity and risk of penile cancer. J Natl Cancer Inst. 1993;85(1):19-24.

12. Morris BJ, Gray RH, Castellsague X, et al. The strong protective effect of circumcision against cancer of the Penis. Adv Urol. 2011;2011:812368.

13. Daling JR, Madeleine MM, Johnson LG, et al. Penile cancer: importance of circumcision, human papillomavirus and smoking in in situ and invasive disease. Int J Cancer. 2005;116(4):606-16.

14. Sand FL, Rasmussen CL, Frederiksen MH, Andersen KK, Kjaer SK. Prognostic significance of HPV and p16 status in men diagnosed with penile cancer: a systematic review and meta-analysis. Cancer Epidemiol Biomarkers Prev. 2018;27(10):1123-32. 
15. Basen-Engquist $\mathrm{K}$, Chang $\mathrm{M}$. Obesity and cancer risk: recent review and evidence. Curr Oncol Rep. 2011;13:71-6.

16. Barnes KT, McDowell BD, Button A, Smith BJ, Lynch CF, Gupta A. Obesity is associated with increased risk of invasive penile cancer. BMC Urol. 2016;16(1):42.

17. Torbrand C, Wigertz A, Drevin L, et al. Socioeconomic factors and penile cancer risk and mortality; a population-based study. BJU Int. 2017;119(2): 254-60.

18. Stern RS. Genital tumors among men with psoriasis exposed to psoralens and ultraviolet A radiation (PUVA) and ultraviolet $\mathrm{B}$ radiation. The Photochemotherapy Follow-up Study. N Engl J Med. 1990;322(16):1093-7.

19. Grulich AE, van Leeuwen MT, Falster MO, Vajdic CM. Incidence of cancers in people with HIV/AIDS compared with immunosuppressed transplant recipients: a meta-analysis. Lancet. 2007;370(9581): 59-67.

20. Morris BJ, Kennedi SE, Wodak AD, et al. Early infant male circumcision: a systematic review, risk-benefic analysis, and progress in policy. World J Clin Pediatr. 2017;6:89-102.

21. Wolbarst A. Circumcision and penile cancer. Lancet. 1932;219:150-3.

22. Daling JR, Sherman KJ, Hislop TG, et al. Cigarette smoking and the risk of anogenital cancer. Am J Epidemiol. 1992;135:180-9.

23. Couto TC, Arruda RM, Couto MC, et al. Epidemiological study of penile cancer in Pernambuco: experience of two reference centers. Int Braz J Urol. 2014;40:738-44.

24. Tsen HF, Morgenstern H, Mack T, et al. Risk factors for penile cancer: results of a population-based casecontrol study in Los Angeles County (United States). Cancer Causes Control. 2001;12:267-77.

25. Villa LL, Lopes A. Human papillomavirus DNA sequences in penile carcinomas in Brazil. Int $\mathrm{J}$ Cancer. 1986;37(6):853-5.

26. Thomas A, Vanthoor J, Vos G, Tsaur I, Albersen M, and in collaboration with the European Reference Network for rare urogenital diseases and complex conditions (eUROGEN). Risk factors and molecular characterization of penile cancer: impact on prognosis and potential targets for systemic therapy. Curr Opin Urol. 2020;30(2):202-7.

27. Public Health Agency of Canada, National Advisory Committee on Immunization. Update on Human
Papillomavirus (HPV) Vaccines. Canada Communicable Disease Report. January 2012;39(ACS-1). https://www.canada.ca/en/public-health/services/ reports-publications/canada-communicabledisease-report-ccdr/monthly-issue/2012-38/canadacommunicable-disease-report.html. Accessed 14 Aug 2017.

28. Shabbir M, Barod R, Hegarty PK, Minhas S. Primary prevention and vaccination for penile cancer. Ther Adv Urol. 2013;5(3):161-9.

29. Schoen EJ. The relationship between circumcision and cancer of the penis. CA Cancer J Clin. 1991;41(5):306-9.

30. Kochen M, McCurdy S. Circumcision and the risk of cancer of the penis. A life-table analysis. Am J Dis Child. 1980;134(5):484-6.

31. Dillner J, von Krogh G, Horenblas S, Meijer CJ. Etiology of squamous cell carcinoma of the penis. Scand J Urol Nephrol Suppl. 2000;205:189-93.

32. Clouston D, Hall A, Lawrentschuk N. Penile lichen sclerosus (balanitis xerotica obliterans). BJU Int. 2011;108(Suppl 2):14-9.

33. Morris BJ, Wamai RG, Henebeng EB, et al. Estimation of country-specific and global prevalence of male circumcision. Popul Health Metr. 2016;14:4.

34. Sorokan ST, Finlay JC, Jefferies AL. Canadian paediatric society, fetus and newborn committee, infectious diseases and immunization committee. Newborn male circumcision. Paediatr Child Health. 2015;20(6):311-20.

35. Morris BJ, Krieger JN, Klausner JD. CDC's male circumcision recommendations represent a key public health measure. Glob Health Sci Pract. 2017;5(1): 15-27. https://doi.org/10.9745/GHSP-D-16-00390 (Published 2017 Mar 28).

36. Chipollini J, Chaing S, Azizi M, Kidd LC, Kim P, Spiess PE. Advances in understanding of penile carcinogenesis: the search for actionable targets. Int J Mol Sci. 2017;18(8):1777.

37. Mannweiler S, Sygulla S, Winter E, Regauer S. Two major pathways of penile carcinogenesis: HPV-induced penile cancers overexpress p16ink4a, HPVnegative cancers associated with dermatoses express p53, but lack p16ink4a overexpression. J Am Acad Dermatol. 2013;69(1):73-81.

38. Sonpavde G, Pagliaro LC, Buonerba C, Dorff TB, Lee RJ, Di Lorenzo G. Penile cancer: current therapy and future directions. Ann Oncol. 2013;24(5): 1179-89. 
39. Guerrero D, Guarch R, Ojer A, et al. Hypermethylation of the thrombospondin-1 gene is associated with poor prognosis in penile squamous cell carcinoma. BJU Int. 2008;102(6):747-55.

40. Cubilla AL, Lloveras B, Alejo A, et al. Value of p16 $(\mathrm{INK})^{4}(\mathrm{a})$ in the pathology of invasive penile squamous cell carcinomas: a report of 202 cases. An J Surg Pathol. 2011;35:253-61.

41. Bethune G, Campbell J, Rocker A, Bell D, Rendon R, Merrimen J. Clinical and pathologic factors of prognostic significance in penile squamous cell carcinoma in a North American population. Urology. 2012;79(5):1092-7.

42. Comperat E. Pathology of penile cancer. Eur Urol Suppl. 2018;17(6):132-7.

43. Kidd LC, Chaing S, Chipollini J, et al. Relationship between human papillomavirus and penile cancer: implications for prevention and treatment. Transl Androl Urol. 2017;6:791-802.

44. Cubilla AL, Ayala A, Ayala G, et al. (2016) Malignant epithelial tumours. In: WHO Classification of Tumours of the Urinary System and Male Genital Organs, 8th, Moch H, Humphry PA, Ulbright TN, Reuter VE (Eds), WHO Press, Lyon 8: 262.

45. Winslow, T., 2017. Anatomy Of The Penis. [image] Available at: <https://visualsonline.cancer.gov/ details.cfm?imageid=11321> [Accessed 17 October 2020].

46. Penile cancer 01, digital photograph, The British Association of Urological Surgeons, < https://www. baus.org.uk/professionals/sections/penile_cancer. aspx $>$ [Accessed 06 December 2020].

47. Ritchie AW, Foster PW, Fowler S. Penile cancer in the UK: clinical presentation and outcome in 1998/99. BJU Int. 2004;94(9):1248-52.

48. Penile cancer lymph nodes, Illustration, The British Association of Urological Surgeons, <https://www. baus.org.uk/professionals/sections/penile_cancer. aspx $>$ [Accessed 06 December 2020].

49. Heyns CF, Mendoza-Valdes A, Pompeo AC. Diagnosis and staging of penile cancer. Urology. 2010;76(2 Suppl 1):S15-23.

50. Skeppner E, Andersson SO, Johansson JE, et al. Initial symptoms and delay in patients with penile carcinoma. Scand J Urol Nephrol. 2012;46:319-25.

51. Fish JA, Prichard I, Ettridge K, Grunfeld EA, Wilson C. Psychosocial factors that influence men's helpseeking for cancer symptoms: a systematic synthesis of mixed methods research. Psychooncology. 2015;24(10):1222-32.
52. Hakenberg OW, Protzel C. Chemotherapy in penile cancer. Ther Adv Urol. 2012;4(3):133-8.

53. Van Poppel H, Watkin NA, Osanto S, Moonen L, Horwich A, Kataja V. Penile cancer: ESMO clinical practice guidelines for diagnosis, treatment and follow-up. Ann Oncol. 2013;24(6):115-24.

54. Pettaway CA, Srigley JR, Brookland RK, et al. Penis. In: Amin MB, Edge SB, Greene FL, et al, editors. AJCC Cancer Staging Manual. 8th ed. New York: Springer; 2017, p. 701.

55. Petralia G, Villa G, Scardino E, et al. Local staging of penile cancer using magnetic resonance imaging with pharmacologically induced penile erection. Radiol Med. 2008;113(4):517-28.

56. Hakenberg OW, Compérat EM, Minhas S, Necchi A, Protzel C, Watkin N. EAU guidelines on penile cancer: 2014 update. Eur Urol. 2015;67(1):142-50.

57. Schlenker B, Scher B, Tiling R, et al. Detection of inguinal lymph node involvement in penile squamous cell carcinoma by $18 \mathrm{f}$-fluorodeoxyglucose PET/CT: a prospective single-center study. Urol Oncol. 2012;30:55-9.

58. National Institute for Clinical Excellence. Improving Outcomes in Urological Cancers. London 2002. Available at: http://www.nice.org.uk. Accessed November 2020

59. Alnajjar HM, Lam W, Bolgeri M, et al. Treatment of carcinoma in situ of the glans penis with topical chemotherapy agents. Eur Urol. 2012;62:923-8.

60. Feldman AS, McDougal WS. Long-term outcome of excisional organ sparing surgery for carcinoma of the penis. J Urol. 2011;186:1303-7.

61. Philippou P, Shabbir M, Malone P, et al. Conservative surgery for squamous cell carcinoma of the penis: resection margins and long-term oncological control. J Urol. 2012;188(3):803-8 (Epub 2012 Jul 19).

62. Bandieramonte G, Colecchia M, Mariani L, et al. Peniscopically controlled $\mathrm{CO} 2$ laser excision for conservative treatment of in situ and $\mathrm{T} 1$ penile carcinoma: report on 224 patients. Eur Urol. 2008;54:875-82.

63. Meijer RP, Boon TA, vanVenrooij GE, Wijburg CJ. Long-term follow-up after laser therapy for penile carcinoma. Urology. 2007;69:759-62.

64. Djajadiningrat RS, Werkhoven EV, Meinhardt W, et al. Penile sparing surgery for penile cancer: does it affect survival? J Urol. 2014;192:120. 
65. Crook JM, Haie-Meder C, Demanes JD, et al. American Brachytherapy Society-Groupe Européen de Curiethérapie-European Society of Therapeutic Radiation Oncology (ABS-GEC-ESTRO) consensus statement for penile brachytherapy. Brachytherapy. 2013;12:191.

66. National Comprehensive Cancer Network (NCCN). NCCN Clinical Practice Guidelines in Oncology: Penile Cancer, version 1, 2013. http://www.nccn. org/ professionals/physician_gls/pdf/penile.pdf. (21 August 2020, date last accessed).

67. Saisorn I, Lawrentschuk N, Leewansangtong S, et al. Fine-needle aspiration cytology predicts inguinal lymph node metastasis without antibiotic pretreatment in penile carcinoma. BJU INt. 2006;97: 1225.

68. Crook J, Ma C, Grimard L. Radiation therapy in the management of the primary penile tumor: an update. World J Urol. 2009;27(2):189-96 (Epub 2008 Jul 18).

69. Rozan R, Albuisson E, Giraud B, Donnarieix D, Delannes M, Pigneux J, Hoffstetter S, Gerbaulet A, Chinet-Charrot P, Goupil A. Intrastitial brachitherapy for penile carcinoma: a multicentric survey (259 patients). Radiother Oncol. 1995;36:83-9.

70. Ficarra V, Akduman B, Bouchot O, et al. Prognostic factors in penile cancer. Urology. 2010;76:S66.

71. Kirrander P, Andren O, Windahl T. Dynamic sentinel node biopsy in penile cancer: initial experiences at a Swedish referral centre. BJU Int. 2013;111:E48-53.

72. Pagliaro LC, Williams DL, Daliani D, et al. Neoadjuvant paclitaxel, ifosfamide, and cisplatin chemotherapy for metastatic penile cancer: a phase II study. J Clin Oncol. 2010;28:3851.

73. Dickstein RJ, Munsell MF, Pagliaro LC, Pettaway CA. Prognostic factors influencing survival from regionally advanced squamous cell carcinoma of the penis after preoperative chemotherapy. BJU Int. 2016;117:118.

74. Djajadiningrat RS, Bergman AM, van Werkhoven E, et al. Neoadjuvant taxane-based combination chemotherapy in patients with advanced penile cancer. Clin Genitourin Cancer. 2015;13:44.

75. Di Lorenzo G, Buonerba C, Federico P, et al. Cisplatin and 5-fluorouracil in inoperable, stage IV squamous cell carcinoma of the penis. BJU Int. 2012;110:E661-6.

76. Theodore C, Skoneczna I, Bodrogi I, et al. A phase II multicentre study of irinotecan (CPT 11) in combination with cisplatin (CDDP) in metastatic or locally advanced penile carcinoma (EORTC PROTOCOL 30992). Ann Oncol. 2008;19:1304.

77. Sharma P, Djajadiningrat R, Zargar-Shoshtari K, et al. Adjuvant chemotherapy is associated with improved overall survival in pelvic node-positive penile cancer after lymph node dissection: a multiinstitutional study. Urol Oncol. 2015;33(11):e17496 (e4.96E23).

78. Robinson R, Marconi L, MacPepple E, et al. Risks and benefits of adjuvant radiotherapy after Inguinal lymphadenectomy in node-positive penile cancer: a systematic review by the european association of urology penile cancer guidelines panel. Eur Urol. 2018;74(1):76-83.

79. Graafland NM, Moonen LM, van Boven HH, et al. Inguinal recurrence following therapeutic lymphadenectomy for node positive penile carcinoma: outcome and implications for management. J Urol. 2011;185:888-93.

80. Montana GS, Thomas GM, Moore DH, et al. Preoperative chemo-radiation for carcinoma of the vulva with N2/N3 nodes: a gynecologic oncology group study. Int $\mathrm{J}$ Radiat Oncol Biol Phys. 2000;48(4):1007-13. https://doi.org/10.1016/ s0360-3016(00)00762-8.

81. Landrum LM, Skaggs V, Gould N, Walker JL, McMeekin DS. Comparison of outcome measures in patients with advanced squamous cell carcinoma of the vulva treated with surgery or primary chemoradiation. Gynecol Oncol. 2008;108(3): 584-90.

82. Homesley HD, Bundy BN, Sedlis A, Adcock L. Radiation therapy versus pelvic node resection for carcinoma of the vulva with positive groin nodes. Obstet Gynecol. 1986;68(6):733-40.

83. Kunos C, Simpkins F, Gibbons H, Tian C, Homesley H. Radiation therapy compared with pelvic node resection for node-positive vulvar cancer: a randomized controlled trial. Obstet Gynecol. 2009;114(3):537-46. https://doi.org/10.1097/AOG. 0b013e3181b12f99.

84. Canter DJ, Nicholson S, Watkin N, Hall E, Pettaway C, InPACT Executive Committee. The international penile advanced cancer trial (InPACT): rationale and current status. Eur Urol Focus. 2019;5(5):706-9.

85. Audenet F, Sfakianos JP. Psychosocial impact of penile carcinoma. Transl Androl Urol. 2017;6(5): 874-8.

86. Haas GP, Blumenstein BA, Gagliano RG, et al. Cisplatin, methotrexate and bleomycin for the treatment of carcinoma of the penis: a southwest oncology group study. J Urol. 1999;161:1823. 
87. Pond GR, Di Lorenzo G, Necchi A, et al. Prognostic risk stratification derived from individual patient level data for men with advanced penile squamous cell carcinoma receiving first-line systemic therapy. Urol Oncol. 2014;32(4):501-8.

88. Necchi A, Eigl BJ, Yang ES, et al. Gene expression profiling of advanced penile squamous cell carcinoma receiving cisplatin-based chemotherapy improves prognostication and identifies potential therapeutic targets. Eur Urol Focus. 2018;4(5): 733-6.

89. Pickering LM, Tovey $\mathrm{H}$, Elliot $\mathrm{T}$, et al. VinCaP: a phase II trial of vinflunine chemotherapy in locallyadvanced and metastatic carcinoma of the penis (CRUK/12/021). J Clin Oncol. 2018;36:547-547. https://doi.org/10.1200/JCO.2018.36.6_suppl.547.

90. Di Lorenzo G, Federico P, Buonerba C, et al. Paclitaxel in pretreated metastatic penile cancer: final results of a phase 2 study. Eur Urol. 2011;60:1280.

91. Jacob JM, Ferry EK, Gay LM, et al. Comparative genomic profiling of refractory and metastatic penile and nonpenile cutaneous squamous cell carcinoma: implications for selection of systemic therapy. J Urol. 2019;201(3):541-8.

92. Chahoud J, McCormick BZ, Netto F, et al. Penile squamous cell carcinoma is genomically similar to other HPV-driven tumors. J Clin Oncol. 2019;37(7_suppl):505-1505.

93. Carthon BC, Ng CS, Pettaway CA, Pagliaro LC. Epidermal growth factor receptor-targeted therapy in locally advanced or metastatic squamous cell carcinoma of the penis. BJU Int. 2014;113(6):871-7.

94. Necchi A, Lo Vullo S, Perrone F, et al. First-line therapy with dacomitinib, an orally available panHER tyrosine kinase inhibitor, for locally advanced or metastatic penile squamous cell carcinoma: results of an open-label, single-arm, single-centre, phase 2 study. BJU Int. 2018;121(3):348-56.

95. Udager AM, Liu TY, Skala SL, et al. Frequent PD-L1 expression in primary and metastatic penile squamous cell carcinoma: potential opportunities for immunotherapeutic approaches. Ann Oncol. 2016;27:1706.

96. Ottenhof SR, Djajadiningrat RS, de Jong J, Thygesen $\mathrm{HH}$, Horenblas S, Jordanova ES. Expression of programmed death ligand 1 in penile cancer is of prognostic value and associated with HPV status. J Urol. 2017;197(3 Pt 1):690-7.

97. Powles T, Park SH, Voog E, et al. Avelumab maintenance therapy for advanced or metastatic urothelial carcinoma. N Engl J Med. 2020;383(13): 1218-30. https://doi.org/10.1056/NEJMoa2002788.

98. Huang T, Cheng X, Chahoud J, et al. Effective combinatorial immunotherapy for penile squamous cell carcinoma. Nat Commun. 2020;11(1): 2124 (Published 2020 May 1).

99. McGregor BA, Campbell MT, Xie W, Farah S, Asim B, Sonpavde G, et al. Phase II study of nivolumab and ipilimumab for advanced rare genitourinary cancers. 2020 ASCO Virtual Scientific Program. J Clin Oncol (2020) 38 suppl:abstr 5018. 